\title{
Racismo e envelhecimento da população negra
}

\author{
Black population racism and aging \\ Racismo y envejecimiento de la población negra \\ Dóris Firmino Rabelo \\ Josevânia da Silva \\ Nara Maria Forte Diogo Rocha \\ Hiago Veras Gomes \\ Ludgleydson Fernandes de Araújo
}

RESUMO: Os entraves dispostos pelo racismo atravessam negativamente a população negra em diversos âmbitos e sentidos. São heranças históricas que se apresentam de forma clara ou velada até os dias atuais e, quando relacionados à velhice, os tópicos que compõem o racismo se amplificam e tomam novas facetas. Conceitos psicossociais são influenciados diretamente pela perpetuação do modelo hierárquico de raças, influindo diretamente nos elementos socioeconômicos, iniquidades em saúde, demandas familiares, violência, entre outras formas desfavoráveis de experiências da população negra, desde o nascimento até a velhice. Dessa forma, a prática psicológica pautada num fazer ético-político se faz necessária, enquanto oposição a tais práticas racistas ainda contemporâneas - marcando-se como propósito deste estudo ratificar essa recomendação; assim, tal prática psicológica mostra sua relevância enquanto práxis científico-metodológica na ruptura com um passado que ainda se faz presente.

Palavras-chave: Racismo; Envelhecimento negro; População negra. 
ABSTRACT: The obstacles posed by racism cross the black population negatively in different spheres and senses. They are legacies of history that present themselves clearly or cover up to the present day, and when related to old age, the topics that make up racism are amplified and take on new facets. Psychosocial concepts are directly influenced by the perpetuation of the hierarchical model of races, directly influencing socioeconomic elements, health inequalities, family demands, violence, among other unfavorable experiences of the black population from birth to old age. In this way, the psychological practice based on an ethical and political action becomes necessary as opposed to such racist practices still contemporary - marking itself as the purpose of this study to ratify this recommendation; Thus, this psychological practice shows its relevance as a scientific and methodological praxis in the rupture with a past that is still present.

Keywords: Racism; Aging black; Black population.

RESUMEN: Los obstáculos dispuestos por el racismo atravesan de forma negativa a la población negra en diversos ámbitos y sentidos. Son herencias de la historia que se presentan de forma clara o cubierta hasta los días actuales, y cuando relacionado a la vejez, los tópicos que componen el racismo se amplifican y toman nuevas facetas. Los conceptos psicosociales son influenciados directamente por la perpetuación del modelo jerárquico de razas, influyendo directamente en los elementos socioeconómicos, desigualdades en salud, demandas familiares, violencia, entre otras formas desfavorables de experiencias de la población negra, desde el nacimiento hasta la vejez. De esta forma, la práctica psicológica pautada en un hacer ético y político se hace necesaria como oposición a tales prácticas racistas aún contemporáneas que se marcan como el propósito de este estudio de ratificar esta recomendación; Así, esta práctica psicológica muestra su relevancia como praxis científica y metodológica en la ruptura con un pasado que aún se hace presente.

Palabras-clave: Racismo; Envejecimiento negro; Población negra. 


\section{Introdução}

A experiência do racismo tem efeito negativo na qualidade de vida e não se resume a respostas provenientes de interações entre indivíduos, mas está profundamente condicionada por fatores estruturais. Devido a práticas discriminatórias com base na raça, os idosos negros têm questões únicas que precisam ser enfrentadas na velhice.

Isso se refere à múltipla desvantagem proveniente das desigualdades econômicas, sociais e históricas, além dos encargos adicionais de viver numa sociedade em que a igualdade racial permanece um mito.

O interesse pelo desenvolvimento típico e pela identificação de padrões de mudança comportamental específicos de um período da vida (Neri, 2013) seriam as delimitações mais repercutidas do que caracterizaria a Psicologia do Desenvolvimento. Contudo, ao buscar o típico, de que idosos estamos falando, e em quais contextos? No Brasil, cuja população se autodeclara majoritariamente negra, esses idosos têm uma menor expectativa de vida em relação aos brancos, sejam homens ou mulheres (Pinheiro, Fontoura, Querino, Bonetti, \& Rosa, 2011; Marcondes, Pinheiro, Queiroz, Querino, \& Valverde 2013).

O surgimento do racismo está diretamente ligado ao contexto de raças e origem da humanidade. Ao longo da história, estudiosos criaram teses para explicar as desigualdades entre os humanos, principalmente baseando-se na genética, ciências físicas e biológicas. Fundamentada na construção histórica da escravidão e colonização, a raça negra sempre fora imposta como inferior à branca. Assim, o racismo ainda é uma realidade atual, promovendo uma perpetuação da crença de que, mesmo com tamanha miscigenação populacional, a cor da pele ainda é uma característica determinista sobre uma pessoa (Munanga, 2004; Alves, 2017).

O racismo, com suas múltiplas determinações, impacta diretamente no processo de envelhecimento da população negra, sendo imprescindível ater-se aos elementos que resultam deste. Para entender como envelhecem, é fundamental conhecer seus indicadores socioeconômicos e de saúde ao longo da vida. E quando se tornam velhos, quais vulnerabilidades e fatores de proteção moldam a experiência do envelhecimento negro? 
Sabe-se que o racismo resulta em desigualdades raciais que colocam a população negra em condições de vulnerabilidades. As práticas discriminatórias revelam-se nas relações interpessoais, na família, na distribuição geográfica dos espaços urbanos, na formação de círculos sociais e nas instituições. Relacionam-se a um conjunto de fatores socioeconômicos e culturais que afetam a saúde física e psicológica, bem como a integridade individual e coletiva.

Nesse contexto, o objetivo deste artigo é discutir o envelhecimento da população negra quanto às condições socioeconômicas, às questões da saúde, das demandas familiares e da violência, bem como a formação e a prática do psicólogo no contexto dos efeitos psicossociais do racismo em idosos.

\section{Condições socioeconômicas}

O envelhecer tem figurado numa perspectiva economicista e demográfica como uma grande preocupação e um fardo. Enfrentamos, no atual contexto político de ruptura democrática (2016-2018), duras pressões para uma reforma da previdência que se traduz na perda de direitos trabalhistas adquiridos com muita luta.

Versões apocalípticas do futuro de um país, no qual a pirâmide demográfica se inverte, são desenhadas como justificativa para a espoliação de uma população já empobrecida. Relações precarizadas de trabalho marcam a trajetória de pessoas negras, (Nobre, 2004; Negro, \& Gomes 2006; Camarano, 2003), sendo que as mulheres negras historicamente figuram em relações de trabalho doméstico, cujas semelhanças com a escravidão não são meras coincidências.

As condições socioeconômicas constituem-se enquanto recursos e desempenham papel importante para o bem-estar na velhice. Baixo nível de escolaridade e baixa renda são indicadores de vulnerabilidade social, que têm efeitos cumulativos prejudiciais ao longo da vida e geram eventos estressantes que se associam às perdas ocasionadas pela diminuição da resiliência biológica e da plasticidade comportamental decorrentes do envelhecimento normal. 
$\mathrm{Na}$ velhice, a pobreza, a baixa escolaridade e a desigualdade social são agravadas pelos preconceitos sociais em relação à idade, e entre os negros também pelo racismo, prejudicando o acesso e a atenção à saúde e à proteção (Neri, 2013).

A população afrodescendente apresenta maior pobreza (brancos no $1 \% \mathrm{com}$ maiores rendimentos e pretos ou pardos entre os mais pobres), menor frequência escolar e acesso ao ensino superior entre jovens, maior incidência de analfabetismo e menor proteção da previdência social (empregados com carteira de trabalho assinada, militares e funcionários públicos estatutários). É predominante no segmento em situação de rua e na população rural (Brasil, 2016).

Em um estudo sobre as configurações acerca da desigualdade dos rendimentos no mercado de trabalho em duas regiões (nordeste e sudeste) em função da raça, foi demonstrado que, para todos os setores de atividades, os negros são discriminados em termos de salário, sendo no Sudeste os maiores índices.

Do mesmo modo, em uma análise das causas que levam a discrepância salarial entre brancos e negros no Brasil e do papel da discriminação racial e dos atributos produtivos na desigualdade salarial, foi demonstrado que os trabalhadores negros têm seu salário reduzido em $17 \%$ em relação aos trabalhadores brancos e que, considerando a educação como mediadora dos valores salariais, para os trabalhadores brancos, o nível educacional traz maior efeito do que para os trabalhadores negros. Ou seja, embora o aumento do nível educacional seja um fator que determine o aumento salarial para brancos e negros, trabalhadores brancos parecem ser mais valorizados no mercado de trabalho.

Nas classes mais elevadas existe uma maior discriminação contra negros, e esta questão torna mais difícil que negros venham a ocupar cargos mais elevados ou posições de chefia dentro das empresas, o que, por seu turno, estaria fadando os negros a se situarem em estratos sociais de subordinação. Classe social e cor, então, apresentariam uma forte relação, no sentido em que aos negros estariam direcionados os menores rendimentos e os cargos inferiores.

Somando-se a isso, temos os efeitos do ageísmo, que difunde o pressuposto da "demografia apocalíptica" quanto às consequências catastróficas do envelhecimento populacional e o mito de que os idosos que estão ativos prejudicam as possibilidades de emprego para os mais jovens. 
Essa discriminação também resulta na limitação de ações compensatórias, como o acesso ao emprego (permanência e inserção em novos empregos), o financiamento de atividades empreendedoras para idosos (Engler, 2007), o investimento à escolarização e à educação voltadas aos mais velhos (Cachioni, \& Falcão, 2009).

O Nordeste tem os maiores índices de analfabetismo do país, e atinge principalmente as populações mais idosas, os negros (quase três vezes maior do que para a população branca), do sexo feminino, e os residentes nas áreas rurais; sendo que quase a metade dos analfabetos encontra-se entre os $25 \%$ mais pobres do país. E nesse contexto, observamos a exclusão de idosos do projeto educacional, com a falta de políticas direcionadas à velhice e ao analfabetismo, inclusive nas leis específicas, como a LDB (da educação) e o Estatuto do Idoso (da velhice) (Peres, 2011).

Também não é por acaso que o espaço periférico das cidades seja constituído por uma maioria de população negra e empobrecida. Seja pela especulação imobiliária ou pelo êxodo rural no desmonte dos quilombos (Carril, 2006), nesses lugares, as idosas inventam redes de solidariedade e apoio, vivenciam sua religiosidade (Santos, 2016) e enfrentam as marcas, rupturas e lutos advindos da precarização e da fragilidade das políticas públicas de saúde, assistência e segurança.

Parte da população negra é remanescente de quilombos de zonas urbanas ou rurais (Haerter, 2010; Santos, 2012; Sampaio, \& Pacheco, 2016) e enfrenta, ainda, a questão da luta pela terra e reconhecimento de sua identidade.

Dados do FIBRA (Neri, 2013) indicam que as piores condições socioeconômicas da população negra mais jovem continuam até a velhice, sugerindo a vigência na privação continuada de benefícios e oportunidades, com impactos negativos na saúde, cognição e bem-estar.

Os idosos negros apresentaram predominantemente baixa renda, baixa escolaridade, maior índice de analfabetismo, vivendo em arranjos domiciliares multigeracionais ou mistos, e com renda familiar percebida pelos próprios idosos como insuficientes para suas necessidades. 


\section{Pessoas idosas negras e iniquidades em saúde}

O envelhecimento é um processo que ocorre ao longo de toda a vida, que envolve perdas e ganhos, e sua vivência particular contribui para o modo como a velhice é concebida por cada sujeito. Por ocorrer dentro de um contexto social e histórico, perpassado por dimensões econômicas e políticas, verifica-se iniquidades em saúde quando se consideram os indicadores em saúde referentes à população de pessoas idosas negras.

Werneck (2016) salienta que o racismo é um dos fatores fundamentais na formulação das iniquidades em saúde que essa parcela populacional vivencia.

O direito à saúde e a condições dignas de atendimento e acesso aos serviços, embora garantido pela Constituição brasileira, nem sempre é respeitado. E quando ocorre, há diferenças em termos de acesso aos serviços de saúde para as pessoas em função do contexto social e da cor da pele. Assim, verificam-se mais doenças e mais mortes em territórios ou segmentos populacionais que vivenciam maior discriminação de direitos. No contexto da velhice, há maiores impactos para as pessoas idosas negras, sobretudo em relação a aspectos como: expectativa de vida, morbimortalidade, saúde da mulher negra, saúde mental, dentre outros aspectos.

Índices verificados na Pesquisa Nacional por Amostra de Domicílios (PNAD, 2012), demonstra que as pessoas negras, com idade acima de 65 anos, correspondem a $43,5 \%$ da população, enquanto a branca é de 55,3\%. Este dado demonstra que a maioria das pessoas que adentram a velhice são brancas. Há que se considerar, ainda, que o aumento populacional de pessoas idosas decorre, dentre outros aspectos, das melhorias ocorridas ao longo do tempo em relação às condições de vida, sobretudo no que se refere ao acesso a serviços de saúde preventivos e curativos. O avanço da tecnologia médica e a ampliação da cobertura de saneamento básico também são fatores a serem considerados, quando se pensa o aumento da expectativa de vida das pessoas. Mesmo com tais avanços na realidade brasileira, o fato de a população idosa apresentar maior índice de pessoas brancas, contrariando o percentual da população geral, aponta para as iniquidades na saúde com impactos negativos para as pessoas negras. 
No que se refere aos indicadores de morbimortalidades, a hipertensão e a diabetes mellitus tem maior risco de morte na população negra. Observa-se maior subdiagnóstico, desassistência, maiores complicações e, por fim, mais mortes (Brasil, 2016). Na velhice, o impacto da hipertensão e diabetes ocasiona problemas relativos à funcionalidade e à qualidade de vida.

Pesquisa realizada no interior da Bahia (Sousa, et al., 2016) com idosos com hipertensão e diabetes mellitus, identificou baixos níveis de qualidade de vida nas facetas Autonomia e Atividades passadas, presentes e futuras. Outro estudo, este de base populacional, que investigou o impacto da hipertensão arterial e diabetes mellitus em idosos, evidenciou que os idosos com mais de uma comorbidade associada apresentaram maiores prejuízos na qualidade de vida (Chin, Lee, \& Lee, 2014).

Destacam-se, ainda, os índices de mortalidade hospitalar. Pesquisa realizada por Santos, et al. (2017) evidenciou maior coeficiente de mortalidade entre idosos negros, indicando uma maior dificuldade de acesso aos serviços da atenção primária à saúde. Ainda segundo os autores, também são escassos os espaços voltados a esse segmento etário de promoção da saúde mental e de prevenção de agravos decorrentes de transtornos mentais.

O racismo repercute negativamente na saúde mental dos indivíduos. Inevitavelmente os estereótipos, preconceitos e discriminações afetam a dinâmica inter e intrapsíquica. Por exemplo, sobre a identidade e a autoimagem pelo modelo ideal de brancura e a consequente negação do corpo e identidade negros. $\mathrm{O}$ racismo, mediante suas situações psiquicamente comprometedoras, também impacta na expressão e na vivência das relações sociais e nos vínculos afetivos amorosos e familiares (Prestes, \& Paiva, 2016).

Ainda no que se refere à saúde mental, além das desigualdades de acesso aos serviços, verifica-se a carência de estudos sobre prevalências de transtornos mentais, segundo grupos raciais na população brasileira.

Sabe-se que a população de cor preta apresenta as maiores taxas de internação hospitalar por transtornos mentais e as iniquidades de acesso ao atendimento hospitalar, observa-se uma proporção maior da mortalidade em relação à internação e pelo uso de drogas (Brasil, 2016). 
Segundo dados da Pesquisa por Amostra de Domicílios de Minas Gerais (Dias, Verona, Gontijo, Estanislau, \& Dias, 2012), a maior parte dos indivíduos com depressão diagnosticada no Estado de Minas Gerais é do sexo feminino, no grupo etário de 60 anos e mais e com maior concentração na população negra.

No tocante ao gênero, são as mulheres negras as mais vulneráveis ao adoecimento, sofrendo com o racismo e com o sexismo. As mulheres são as principais vítimas das causas de mortalidade materna (hipertensão, infecção puerperal, aborto e hemorragia). Diferentemente dos homens, as violências não resultam necessariamente em óbito ou internações, mas repercutem no perfil de morbidade (Brasil, 2016). Ainda, estão mais expostas à privação de direitos humanos e não contam com programas governamentais eficientes na garantia do direito à educação e à saúde integral (Prestes, \& Paiva, 2016).

Em face a tais demandas, a atenção à saúde da população negra, incluindo as pessoas idosas, tem sido objeto de políticas públicas de saúde no Brasil, as quais têm procurado dar respostas no que tange à efetivação do direito humano à saúde (Gomes, Damasceno, Nery, Martins Filho, \& Vilela, 2017).

Nessa direção, em 10 de novembro de 2006, o Conselho Nacional de Saúde aprovou a Política Nacional de Saúde Integral da População Negra (PNSIPN). Mas foi em maio de 2009, que a PNSIPN foi Instituída pela Portaria n. ${ }^{\circ}$ 992. A Política Nacional de Saúde Integral da População Negra tem como objetivo "Promover a saúde integral da população negra, priorizando a redução das desigualdades étnico-raciais, o combate ao racismo e à discriminação nas instituições e serviços do SUS" (Brasil, 2016). Dentre as estratégias de gestão da política, destaca-se a procura pelo fortalecimento da atenção à saúde integral da população negra em todas as fases do ciclo da vida, o que é importante para a redução das vulnerabilidades em saúde na velhice.

A PNSIPN destaca o fortalecimento da "atenção à saúde mental das crianças, adolescentes, jovens, adultos e idosos negros, com vistas à qualificação da atenção para o acompanhamento do crescimento, desenvolvimento e envelhecimento e a prevenção dos agravos decorrentes dos efeitos da discriminação racial e exclusão social" (Brasil, 2016). Este olhar longitudinal para as implicações dos processos de discriminação e exclusão ao longo de desenvolvimento humano é importante no combate às iniquidades em saúde. 
Ademais, reconhecer o racismo como um determinante social dos processos de saúde e doença pode ser um indicador importante da maturidade das instituições no enfrentamento das desigualdades que têm relação com a raça ou pela cor da pele (Gomes. et al., 2017).

\section{Demandas familiares}

O racismo e o ageism não é um conjunto de repressões fixas. Entender a estrutura e o funcionamento de famílias negras em um contexto social de dominação, opressão, mistificação e exploração envolve conhecer alguns mecanismos operantes, inclusive na fase da velhice. A história das famílias está conectada com o pessoal e o político, o privado e o público, o individual e o coletivo.

Frente ao modelo tradicional dominante de família branca, patriarcal e heterossexual, as famílias negras foram estereotipadas como incompletas, instáveis, desorganizadas, disfuncionais, incompetentes, com uniões promíscuas e ilegítimas; e seus tipos distintos desconhecidos ou ignorados (Hita, 2005).

A família está sujeita a forças sociais e opressoras que vão além do seu controle, de maneira que os problemas nas interações intrafamiliares não podem ser única e exclusivamente de responsabilidade de seus membros, tanto na criação quanto na manutenção dessas dificuldades. Nesse contexto, não se trata apenas dos arranjos de poder intrafamiliares, mas da desigualdade de poder das famílias negras em relação a famílias brancas na sociedade, e as diferenças de posição política e econômica. Essa desigualdade afeta o acesso das famílias aos recursos, nas tarefas próprias do ciclo familiar, na conquista educacional e, por consequência, na renda. As dificuldades que as famílias negras enfrentam no seu funcionamento têm relação com a opressão social (Green, 2003).

Os efeitos residuais do passado escravocrata reforçaram uma identidade fragmentada e negativa. Considerando a sólida identidade da ancestralidade africana quando vieram para o Brasil (a maioria do oeste africano, da Nigéria e Angola atuais, com seus sistemas tradicionais Iorubá e Banto-Congo), a não existência dos negros na consciência da sociedade mais ampla tem consequências importantes (Nogueira, 2014). 
Exemplos da obliteração sistemática da existência, residuais da escravidão, incluem a anulação do homem negro pela omissão da paternidade, a imposição do "nãoself' ou a diferenciação deficiente do self imposta pela identificação com o opressor e dominante, a vulnerabilidade ao corte emocional pela divisão sistemática e involuntária das famílias e da sua linhagem tradicional, pela internalização de estereótipos negativos (burros, sujos, maus, fixados em sexo, agressivos) e os efeitos psicossociais resultantes dos esforços de manter ocultos eventos familiares emocionalmente carregados (perdas, abusos, mitos, segredos) (Pinderhughes, 2003).

Outra questão familiar é o chamado duplo vínculo racista. Um relacionamento de duplo vínculo é um padrão de comunicação familiar, explícita e implícita, em que uma pessoa mais poderosa tiraniza e vitimiza outra menos poderosa.

Opera através de mensagens sutis e contraditórias, comunicando de maneira mistificadora o que vincula o alvo (por exemplo, dizer num contexto atormentador "Eu não te tratei sempre bem?" ou "Você deve estar louco!"), gerando ansiedade, insegurança e dúvidas. Essas estratégias são usadas a serviço do racismo, quando, para ser reconhecido, é necessário rejeitar sua identidade racial, situações de abuso tirânico que geram estresse pós-traumático e hipervigilância nas famílias ou ficar preso ao paradoxo de mostrar-se corajoso e valente para a família e, ao mesmo tempo, precisar ser salvo do perigo (Mahmoud, 2003).

São várias as demandas e as dificuldades ao longo do ciclo vital. Por exemplo, os filhos de mulheres negras têm maior chance de terem os pais ausentes, seja pelo abandono, morte ou encarceramento. O racismo afeta os casais negros e os inter-raciais, as práticas de socialização da família, bem como regula as preferências afetivas das pessoas (contribuindo para a solidão da mulher negra). A maior parte da coorte atual de idosas negras descende da zona rural, do trabalho doméstico, de atividades manuais subalternas ou do mercado informal. Muitas dessas mães precisaram ausentar-se de casa para trabalhar em casas de famílias brancas, e frequentemente exercendo o papel de babás. É comum a memória dos filhos com relação ao tratamento diferencial percebido entre eles (de carência materna) e os filhos dos patrões (tratamento mais amoroso e complacente) (Pacheco, 2013). 
Contrapondo-se ao modelo da "mãe solteira" e ao modelo nuclear, destaca-se o modelo de família extensa matriarcal (matriarcalidade negra geralmente chefiada por velhas). Esse tipo de família não é o único modelo entre negros, mas está relacionado a uma matriz cultural africana. Essa estrutura ressalta a importância da mulher na operação das redes sociais de parentesco e a centralidade da díade mãe-filhos, que nada tem de patológico ou desviante. A figura da mulher-mãe-avó é central e é ela quem tem a posse da casa, da chefia familiar e dos principais recursos para a manutenção do grupo doméstico. Existe nesse modelo um circuito de reciprocidade obrigatória no seio familiar, e negar esse sistema é visto como ingratidão e renúncia. Nesse arranjo a presença do homem não é nula ou insignificante, pois é ele, principalmente um filho consanguíneo, quem exerce um papel de mediador com a sociedade mais ampla, e é nele que as mulheres depositam suas expectativas e esperanças de proteção e autoridade (Hita, 2005).

Por outro lado, as trajetórias, e o modo de vida desses grupos domésticos refletem as restrições econômicas e sociais sofridas no curso de vida, principalmente na velhice. Relações de afeto, conflito e poder, com todas as suas ambivalências e contradições, são moldadas nesse contexto por uma gama de estratégias individuais e coletivas. Isso indica que, mesmo em modelos cuja mulher idosa é central e acumula poder na hierarquia familiar, arranjos multigeracionais são formados pelas necessidades físicas, sociais, afetivas e materiais de seus membros, e muitas vezes isso custa caro ao idoso. Essas idosas acumulam as funções de provedora e cuidadora, mesmo em condições em que elas próprias precisam ser cuidadas, com impacto negativo na sua saúde mental e na sua percepção de funcionalidade familiar (Rabelo, \& Neri, 2015).

$\mathrm{O}$ simbolismo de guerreira associado às mulheres negras, ao mesmo tempo em que honra a força delas, também corresponde a uma exigência contingente às adversidades e uma necessidade a despeito de satisfações pessoais, o que as sobrecarrega de modo desigual. De uma perspectiva psicossocial, esse estereótipo, fruto das vivências, está acompanhado de comprometimentos psicológicos, adoecimentos e sofrimento psíquico (Pacheco, 2013). 
No enfrentamento dos contextos de alta vulnerabilidade a que estão expostas, as mulheres negras são apoiadas pelas experiências coletivas e transgeracionais, isto é, suas experiências e instâncias de pertencimento, suas trajetórias, suas redes, comunidades e territórios. A transmissão psíquica transgeracional dos laços de coesão entre mulheres negras, da rede de suporte social e os movimentos de resistência na superação do racismo contribuem para a construção de uma identidade coletiva positiva e afirmativa. O processo de resiliência e a disponibilidade de recursos internos que a facilitam, iniciam-se na família e no seu percurso psicoafetivo. Favorecem processos de resiliência a autoconfiança, pertencimento, bom relacionamento familiar/social, suporte social e autonomia (Prestes, \& Paiva, 2016).

\section{Violência}

Dados de violência indicam maior prevalência de pretos em lutas físicas, em agressões físicas causadas por um adulto da família, sendo que as principais causas de óbitos envolvem o homicídio e acidentes de trânsito.

Os homens jovens sofrem mais violência que levam a óbito e é a maior parte da população carcerária brasileira. Negros somam mais da metade das vítimas de violência homofóbica (Brasil, 2016).

As estatísticas que são apresentadas sobre o índice de violência em relação à população negra influem pontualmente no pensar enquanto processo de envelhecimento dessa parcela populacional. A população idosa brasileira ter uma maior porcentagem de brancos, indicando que o racismo tem impacto na longevidade de negros, especialmente entre homens (Brasil, 2016).

A violência em relação à pessoa negra está para além do campo físico, extrapolando as barreiras do corpo e se apresentando com atravessamentos relacionados ao enxergar-se enquanto humano, influenciando de modo direto a saúde mental deste (Sinhoretto, \& Morais, 2018). O corpo negro desde sua infância é, para a sociedade, mais vulnerável a uma intervenção violenta. 
A violência constituída ao longo do tempo para com o negro visa, de forma velada, a apagá-lo e a desumanizá-lo como uma forma de limpeza social. A vida negra em si é uma grande luta política frente à estrutura de poder na qual a sociedade está imersa (Werneck, 2016).

Assim como a trajetória de vida complexa da população negra, o envelhecimento destas pessoas também sofre árduas consequências. Excedendo as vias comuns de violência, tais como a física e a psicológica, os negros também estão enraizados a perfis de violências sociais, interpessoais e familiares. Lago, Cavalcante e Luz (2014) discutem acerca do perfil de tais violências, pois o gênero se mostra como fator determinante para a propagação do exercício de dominação e exploração.

A predominância do homem branco, adulto, e de classe alta sobre mulheres, crianças, idosos, pobres e negros revela o perfil de maior preponderância no que tange aos aspectos de violência. Assim, a mulher negra, idosa e pobre está mais sujeita ao risco de sofrimento quanto aos aspectos supracitados; porém, alguns elementos quando presentes podem aumentar as chances dessas práticas, tais como: dependência financeira, uso de substâncias psicoativas, laços afetivos desarmoniosos ou histórico de violência (Lago, Cavalcante, \& Luz, 2014).

Os impactos provocados por violência e por aspectos do racismo são catastróficos e incidem sem desvios na produção de uma velhice negra considerada desassistida.

Assim como Souza e Minayo (2010) analisaram, vale ressaltar que os aspectos expostos estatisticamente são baseados na parcela de casos que chegam ao conhecimento dos serviços relacionados. Supõe-se que parte da violência velada que existe no âmago da presente civilização ainda não possui estruturas suficientes para ser observada, pois ainda se trata de uma naturalidade construída historicamente.

O racismo como forma direta de violência implica na necessidade de atenção aos processos minoritários de uma sociedade hierarquizada. As consequências que advêm dessa prática resultam em saldos negativos de proteção e assistência ao qual o próprio Estado se propõe a disponibilizar. As políticas públicas de saúde voltadas ao idoso são conquistas ainda conceitualmente teóricas em sua maioria, e, frequentemente apresentadas como falhas ao analisar sua eficácia frente à população idosa negra. 
O racismo enraizado, e como fator de sofrimento e violência psíquica, carece de uma visão demasiadamente aberta à racionalidade, pois só se concretizará um futuro igualitário com a superação do modelo de passado injusto ao qual fora imposto tal população (Souza, \& Minayo, 2010; Werneck, 2016).

\section{Efeitos psicossociais do racismo em idosos: formação e prática do psicólogo}

Resultante de uma criação ideológica de raças superiores e inferiores, o racismo é atravessado por resultados negativos e efeitos psicossociais. O modo no qual ocorreu, e ocorre, o processo de subjetivação dessa parcela populacional está vinculado à sua concepção de sujeito social. Intitulados como subalternos e como pertencentes às parcelas mais baixas da sociedade, os negros foram sempre excluídos da política e da representação enquanto cidadão, ou mesmo sujeitos "assujeitados", uma caracterização relacionada à invisibilidade dada pelo racismo ao negro durante sua vida (Santos, 2015).

Não obstante a participação majoritária do negro em minorias, e no que tange os aspectos econômicos negativos de uma nação, o racismo construiu vertentes que se entrelaçam e integram outros pontos da vida em sociedade. Ramificações como o racismo institucional, interpessoal e internalizado são diferentes formas de como o fenômeno pode se apresentar na construção social de uma coletividade.

As diversas formas supramencionadas de racismo podem ser vivenciadas de forma cotidiana pela população negra, partindo de bens primários como a saúde pública, chegando até mesmo à discriminação dos negros por seus semelhantes (Sinhoretto, \& Morais, 2018).

Perpassando por todos os contextos históricos de exclusão, do escravismo ao racismo, das teorias racialistas e do branqueamento e democracia racial, as velhices e o envelhecimento negro se constituem enquanto mais um enquadre minoritário. $\mathrm{O}$ termo idoso negro refere-se, na maioria das vezes, segundo os dados demográficos, às minorias de pobreza, baixa escolaridade, desemprego e outras tantas possíveis mazelas sociais. Para Santos (2015), embora os termos e argumentos sofram alterações, a continuidade dada aos ajustes raciais se apropria cada vez mais de discursos que buscam efetivar a dominação hierárquica. 
Considerando todo o arcabouço fornecido pelo enraizamento do racismo e seu histórico, pode-se analisar que os idosos negros atuais são minoria, e isso é fruto de um passado obscuro. A população idosa brasileira é, em sua maioria, branca; assim, pode-se ponderar sobre o período escravocrata, quando a expectativa de vida negra variava em torno dos 19 anos. Ao imaginar uma linha tênue entre processos de envelhecimento entre brancos e negros, percebe-se a existência de uma variância e contraste considerável entre ambos, isso devido à estruturação coletiva dada naquela época, baseada em determinações realizadas pela cor da pele e que se estende até os dias atuais (Nogueira, 2011).

A velhice negra de hoje foi formada a partir de constituições desproporcionais; logo, entende-se que tal parcela corrobora a ideia de que o processo de envelhecimento é multideterminado. Fica claro que a complexidade da velhice não se resume apenas em meras junções de elementos, poi, a chegada do negro à velhice depende de inúmeras variáveis, principalmente de condições materiais objetivas. Desse modo, ao refletir sobre o histórico desigual no qual a população negra se findou durante toda a vida, é indiscutível que seu envelhecimento também será vivenciado de maneira desigual (Oliveira, 2016).

A Psicologia enquanto práxis e saber científico se encaixa nesse contexto e possui, teoricamente, o papel de se opor às diversas formas de opressão e sofrimento humano.

A presença de um pensar psicológico em questões como o racismo e o envelhecimento negro é de suma importância, e apresenta-se como uma aliada na luta criada por movimentos sociais e reivindicações face às inúmeras desigualdades sofridas ao longo do tempo por essa população (Werneck, 2016).

Historicamente Schultz e Schultz (2007) consideram o preconceito e a discriminação como forças contextuais que moldam o desenvolvimento da ciência psicológica, sobretudo nos Estados Unidos. Dada numa construção em tempos hierarquizados, a Psicologia se fundou e por muito tempo trabalhou em função de práticas excludentes e racistas. Atualmente, na busca constante por uma prática estéticopolítica, o profissional de Psicologia deve se fixar em uma atuação inclusiva, na tentativa de abarcar os mais diversos sofrimentos psíquicos e de suprir o que já fora negligenciado anteriormente (CFP, 2017). 
A implementação da temática racismo deve fazer parte da formação em Psicologia, pois é uma realidade do contexto nacional que opera nas relações sociais e nos diversos tipos de sofrimento psíquico. Visando à afinidade com tais objetos é possível que o profissional formado seja exemplo na sociedade, atuando na desconstrução de preconceitos e de práticas discriminatórias. Compreendendo as diversas formas de relações raciais presentes na atualidade, promoverá um melhor manejo acerca de sofrimentos psíquicos de pessoas negras, em instituições, escolas, trabalho, família e outras diversas relações sociais (CFP, 2017).

O Código de Ética do psicólogo prevê, por lei, princípios que orientam a prática profissional de modo coesa e comprometida com o bem-estar dos indivíduos. Segundo o CFP (2017), a formação do profissional de Psicologia deve atentar-se aos saberes dos mais variados assuntos vividos no cotidiano dos sujeitos, assim como o racismo e o envelhecimento. Dessa forma, a aproximação de estudantes e profissionais com tais temas relevantes proporciona o reconhecimento e interesse, ao passo que edificará uma formação crítica e reflexiva, desconstruindo o racismo e promovendo maior equidade, sendo assim capazes de originarem assistências interventivas e coerentes.

\section{Considerações Finais}

A velhice negra e seus constantes desafios discutidos devem ser observados como forma de resistência e posicionamento de um ser humano enquanto cidadão. Os entraves sociais postos à população negra, de modo geral, são heranças que estão distantes de serem abandonadas, tanto pela presença continuada de um passado, como pela perpetuação de um modelo hierarquizado e hegemônico. As diferenças socioeconômicas, a desassistência social e a violência são resultantes de uma classificação construída sob uma ótica negligente ainda existente.

A Psicologia como espaço de formação e atuação ético-política entrelaça-se fielmente e possui dever fundamental na atual discussão. A construção de um saber baseado em dados históricos de luta e opressão fazem com que cada vez mais as temáticas minoritárias façam parte da constituição ética do profissional de Psicologia. 
Voltar o olhar e aproximar-se dos fatos cotidianos que corroboram e impulsionam sofrimentos humanos é o primeiro passo para a formulação de uma prática racional e interventiva, para que, assim, oferecendo espaço para a concepção de novos ideais, busque-se uma equidade ainda utópica.

É preciso partir da crítica política ao conceito de raça, bem como ao sistema de exclusão por ele engendrado, o racismo. Sua manutenção apoia-se na cegueira produzida pelo Iluminismo no tocante ao tráfico humano que serviu de base econômica para o sistema colonial, perpetuando-se para além do fim desse regime político (Quijano, 2010). Enquanto não é possível à racionalidade vigente reconhecer as operações ancoradas na raça, os não-brancos são continuamente endereçados ao mesmo lugar negativo que ela pressupõe para eles na partilha da humanidade. O paradigma no qual se assenta é aquele que atribui aos diferentes a anormalidade. $O$ saber científico, que, por muito tempo, se ateve às práticas de hegemonia e exclusão, hoje se apresenta como uma oportunidade de reedificação de conceitos disfuncionais, como o próprio racismo.

Desse modo, entender como tal fenômeno atua, suas causas e consequências, são formas coerentes de trabalho enquanto formação de discursos congruentes. O trabalho de escuta junto àqueles que sempre foram omitidos faz da ciência um instrumento com propósitos e intenções; logo, resultando numa eficaz ferramenta de transformação.

Isso exige uma séria consideração dos limites e possibilidades desta escuta, como aponta Spivak (2010), exigindo do psicólogo uma profunda problematização dos sustentáculos do racismo em nossa sociedade.

Assim sendo, o presente escrito objetivou contribuir para a literatura científica enquanto práxis psicológicas de transformação coletiva, pondo em questão as objeções sofridas pela população idosa negra, com o intuito de propagar e amplificar o espaço de fala e argumentação sobre tal temática, ademais, conjuntamente pautada numa atuação psicológica enquanto agente social contemporâneo. 


\section{Referências}

Alves, T. (2017). O conceito de raça e identidade étnico-racial: aspectos históricos Trabalho de conclusão de curso) Universidade Estadual da Paraíba, UEPB, Guarabira, PB, Brasil. Recuperado em 19 outubro, 2017, de: http://dspace.bc.uepb.edu.br/jspui/handle/ $123456789 / 14216$.

Brasil. (2012). Governo Federal. Pesquisa Nacional por Amostra de Domicílio, PNAD 2012, Recuperado em 19 outubro, 2017, de: https://www.ibge.gov.br/estatisticasnovoportal/ multidominio/ciencia-tecnologia-e-inovacao/9127-pesquisa-nacional-poramostra-de-domicilios.html?\&t=downloads.

Brasil. (2016). Governo Federal. Painel de indicadores do SUS n. ${ }^{\circ}$ 10: Temático saúde da população negra. Brasília, DF: Ministério da Saúde. Recuperado em 19 outubro, 2017, de: http://bvsms.saude.gov.br/bvs/publicacoes/tematico_saude_populacao_negra_v._7.pdf.

Cachioni, M., \& Falcão, D. V. S. (2009). Velhice e educação: possibilidades e benefícios para a qualidade de vida. In: Falcão, D. V. S., \& Araújo, L. F. (Orgs.). Psicologia do Envelhecimento: relações sociais, bem-estar subjetivo e atuação profissional em contextos diferenciados, 175-212. Campinas, SP: Alínea.

Camarano, A. A. (2003). Mulher idosa: suporte familiar ou agente de mudança? Estudos Avançados, 17(49), 35-63. Recuperado em 19 outubro, 2017, de: http://www.scielo.br/pdf/ea/v17n49/18396.pdf.

Carril, L. (2006). Quilombo, favela e periferia: a longa busca da cidadania. São Paulo, SP: Annablume.

Chin, Y. R., Lee, I. S., \& Lee, H. Y. (2014). Effects of hypertension, Diabetes, and/or Cardiovascular Disease on Health - related Quality of Life in Elderly Korean Individuals: A Population - based Cross - sectional Survey. Asian Nursing Research, 1(8), 267-273. Recuperado em 19 outubro, 2017, de: doi: 10.1016/j.anr.2014.10.002.

Conselho Federal de Psicologia, CFP. (2017). Relações Raciais: Referências técnicas para atuação de psicólogas/os. Brasília, DF: CFP.

Dias, F. M. V., Verona, A. P. A., Gontijo, B. A., Estanislau, B. R., \& Dias Júnior, C. S. (2012). Perfil dos indivíduos diagnosticados com depressão maior no Estado de Minas Gerais, Brasil. R. Bras. Est. Pop., 29(2), 497-502. Recuperado em 19 outubro, 2017, de: http://www.scielo.br/pdf/rbepop/v29n2/a16v29n2.pdf.

Engler, T. (2007). Como a economia pode favorecer a construção de uma velhice bemsucedida. In: Neri, A. L. Qualidade de vida na velhice: enfoque multidisciplinar, 83126. Campinas, SP: Alínea.

Gomes, I. C. R., Damasceno, R. O., Nery, A. A., Martins Filho, I. E., \& Vilela, A. B. A. (2017). Implementação da política nacional de atenção integral à saúde da população negra na Bahia. Rev. Baiana Enfermagem, 31(2), 1-12. Recuperado em 19 outubro, 2017, de: doi: http://dx.doi.org/10.18471/rbe.v31i2.21500.

Green, R. (2003). Programas de treinamento: guias para a transformação multicultural. In: Mcgoldrik, M. (Org.). Novas abordagens da terapia familiar: raça, cultura e gênero na prática clínica, 127-134. São Paulo, SP: Roca. 
Haerter, L. (2010). Uma etnografia na comunidade negra rural Cerro das Velhas: memória coletiva, ancestralidade escrava e território como elementos de sua autoidentificação quilombola. Dissertação de mestrado. Instituto de Sociologia e Política, Universidade Federal de Pelotas, Pelotas, RS, Brasil.

Hita, M. G. (2005). Geração, raça e gênero em casas matriarcais. In: Motta, A. B, Azevedo, E. L., \& Gomes, M. (Orgs). Reparando a falta: dinâmica de gênero em perspectiva geracional. Salvador, BA: UFBA, 77-89.

Lago, E. A., Cavalcante, T. B., \& Luz, M. H. B. A. (2014). Violence against elderly: a review of literature. Rev. Saúde.com, 10(2), 221-231. Recuperado em 19 outubro, 2017, de: https://www.ingentaconnect.com/content/doaj/18090761/2014/00000010/00000002/art00019.

Mahmoud, V. M. (2003). Os duplos vínculos do racismo. In: McGoldrik, M. (Org.). Novas abordagens da terapia familiar: raça, cultura e gênero na prática clínica, 293307. São Paulo, SP: Roca.

Marcondes, M. M., Pinheiro, L., Queiroz, C., Querino, A. C., \& Valverde, D. (2013). Dossiê mulheres negras: retrato das condições de vida das mulheres negras no Brasil, 50-68. Brasília, DF: Instituto de Pesquisa Econômica Aplicada.

Munanga, K. (2004). Rediscutindo a mestiçagem no Brasil: Identidade nacional versus identidade negra. Belo Horizonte, MG: Autêntica.

Negro, A. L., \& Gomes, F. (2006). Além de senzalas e fábricas: uma história social do trabalho. Tempo Social, 18(1), 217-240. Recuperado em 19 outubro, 2017, de: http://www.scielo.br/pdf/ts/v18n1/30015.pdf.

Neri, A. L. (2013). Conceitos e teorias sobre o envelhecimento. In: Malloy-Diniz, L., Fuentes, D., \& Cosenza, R. M. Neuropsicologia do envelhecimento: uma abordagem multidimensional, 17-42. Porto Alegre, RS: Artmed.

Nobre, M. (2004). Trabalho doméstico e emprego doméstico. In: Costa, A. A. et al. (Orgs.). Reconfiguração das relações de gênero no trabalho, 61-69. São Paulo, SP: CUT Brasil.

Nogueira, L. F. V. (2011). Expectativa de vida e mortalidade dos escravos. Histórica, 51(1), 22-45. Recuperado em 19 outubro, 2017, de: http://www.arquivoestado.sp.gov.br/site/assets/publicacao/anexo/historica51.pdf.

Nogueira, S. G. (2014). Políticas de identidade, branquitude e pertencimento étnicoracial. In: Bento, M. A. S., Silveira, M. J., \& Nogueira, S. G. (Orgs.). Identidade, branquitude e negritude - contribuições para a Psicologia Social no Brasil: novos ensaios, relatos de experiência e de pesquisa, 49-64. São Paulo, SP: Casa do Psicólogo.

Oliveira, I. C. (2016). Mulheres negras idosas: a invisibilidade da violência doméstica Tese de doutorado. Pontifícia Universidade Católica de São Paulo, PUC-SP, São Paulo, SP, Brasil. Recuperado em 19 outubro, 2017, de: https://sapientia.pucsp.br/ bitstream/handle/19434/2/Ilka\%20Cust\%c3\%b3dio\%20de\%20Oliveira.pdf.

Pacheco, A. C. L. (2013). Mulher negra: afetividade e solidão. Salvador, BA: Edufba.

Peres, M. A. C. (2011). Velhice e analfabetismo, uma relação paradoxal: a exclusão educacional em contextos rurais da região Nordeste. Revista Sociedade e Estado, 26(3), 631-661. Recuperado em 19 outubro, 2017, de: http://dx.doi.org/10.1590/S010269922011000300011. 
Pinderhughes, E. (2003). Genealogia negra revisitada: re-historiando uma família afroamericana. In: Mcgoldrik, M. (Org.). Novas abordagens da terapia familiar: raça, cultura e gênero na prática clínica, 203-226. São Paulo, SP: Roca.

Pinheiro, L., Fontoura, N. O., Querino A. C., Bonetti, A., \& Rosa, W. (2011). Retrato das desigualdades de gênero e raça. Brasília, DF: IPEA, 50-69.

Prestes, C. R. S., \& Paiva, V. S. F. (2016). Abordagem psicossocial e saúde de mulheres negras: vulnerabilidades, direitos e resiliência. Saúde Soc., 25(3), 673-688. Recuperado em 19 outubro, 2017, de: http://dx.doi.org/10.1590/s0104-129020162901.

Quijano, A. (2010). Colonialidade do poder e classificação social. In: Santos, B. S., \& Meneses, M. P. (Orgs.). Epistemologias do Sul, 85-109. São Paulo, SP: Cortez.

Rabelo, D. F., \& Neri, A. L. (2015). The household arrangements, physical and psychological health of the elderly and their satisfaction with family relationships. Rev. Bras. Geriatr. Gerontol., 18(3), 507-519. Recuperado em 19 outubro, 2017, de: http://dx.doi.org/10.1590/1809-9823.2015.14120.

Sampaio, A. C., \& Pacheco, A. C. (2016). Mulheres griôs quilombolas: um estudo inicial sobre identidade de gênero e identidade étnica. Pontos de Interrogação - Revista de Crítica Cultural, 5(2), 55-70. Recuperado em 19 outubro, 2017, de: https://docplayer.com.br/47092689-Pontos-de-interrogacao-revista-de-critica-cultural.html.

Santos, G. (2015). Racismo institucional: uma análise a partir da perspectiva dos estudos póscoloniais e da ética. Ensaios Filosóficos, 11(1), 145-165. Recuperado em 19 outubro, 2017, de: http://www.ensaiosfilosoficos.com.br/Artigos/Artigo11/ GisleneAparecidadosSantos.pdf.

Santos, M. J. (2012). Trajetórias educacionais de mulheres quilombolas no Quilombo das Onze Negras no Cabo de Santo Agostinho, PE. Dissertação de mestrado. Faculdade de Educação da Pontifícia Universidade Católica de São Paulo, PUC-SP, São Paulo, SP, Brasil.

Santos, N. M. (2016). Negras velhas: um estudo sobre seus saberes nas perspectivas de envelhecimento, trabalho, sexualidade e religiosidade. Dissertação de mestrado. Faculdade de Educação da Universidade Federal do Rio Grande do Sul, Porto Alegre, RS, Brasil.

Santos, V. C., Anjos, K. F. dos, Boery, R. N. S. de O., Moreira, R. M., Cruz, D. P., Boery, E. N. (2017). Internação e mortalidade hospitalar de idosos por transtornos mentais e comportamentais no Brasil. Epidemiol. Serv. Saúde, 26, 39-49. Recuperado em 19 outubro, 2017, de: doi: 10.5123/S1679-49742017000100005.

Sinhoretto, J., \& Morais, D. (2018). Violência e racismo: novas faces de uma afinidade reiterada. Revista de Estudios Sociales, 35(64), 15-26. Recuperado em 19 outubro, 2017, de: https://journals.openedition.org/revestudsoc/10010.

Souza, E. R., \& Minayo, M. C. S. (2010). Inserção do tema violência contra a pessoa idosa nas políticas públicas de atenção à saúde no Brasil. Ciência \& Saúde Coletiva, 15(6), 2659-2668. Recuperado em 19 outubro, 2017, de: https://doi.org/10.1590/S141381232010000600002.

Spivak, G. C. (2010). Pode o subalterno falar? Belo Horizonte, MG: Editora UFMG. 
Werneck, J. (2016). Racismo institucional e saúde da população negra. Saúde e Sociedade, 25(3), 535-549. Recuperado em 19 outubro, 2017, de: https://doi.org/10.1590/s0104-129020162610.

Recebido em 26/07/2018

Aceito em 30/09/2018

Dóris Firmino Rabelo - Psicóloga. Doutorado em Educação e Mestrado em Gerontologia, Universidade Estadual de Campinas, Brasil. Docente do Centro de Ciências da Saúde, Universidade Federal do Recôncavo da Bahia, Brasil, do Programa de Pós-Graduação em Psicologia, da Universidade Federal da Bahia, UFBA, e do Mestrado Profissional em Saúde da Família, ProfSaúde, ABRASCO.

URL: https://orcid.org/0000-0002-0791-7781

E-mail: drisrabelo@yahoo.com.br

Josevânia da Silva - Professor Adjunto da Universidade Estadual da Paraíba, Brasil. Docente do Departamento de Psicologia e do Programa de Pós-Graduação em Psicologia da Saúde, da Universidade Estadual da Paraíba, UEPB, Brasil. Doutorado em Psicologia (Psicologia Social), Universidade Federal da Paraíba, UFPB/João Pessoa, URL: https://orcid.org/0000-0003-3344-3791

E-mail: josevaniasco@gmail.com

Nara Maria Forte Diogo Rocha - Professora da Universidade Federal do Ceará. Doutorado em Educação, Universidade Federal do Ceará.

URL: https://orcid.org/0000-0001-5040-1492

E-mail: narafdiogo@gmail.com 
Hiago Veras Gomes - Acadêmico do curso de Bacharelado em Psicologia, Universidade Federal do Piauí, UFPI, Departamento de Psicologia, Universidade Federal do Piauí.

URL: https://orcid.org/0000-0002-8547-8649

E-mail: hiagoveras@hotmail.com

Ludgleydson Fernandes de Araújo - Doutor em Psicologia, Universidad de Granada, Espanha. Pesquisador, Docente, Departamento de Psicologia, Universidade Federal Piauí. Bolsista de Produtividade em Pesquisa 2. Orientador de Doutorado. Programa de Pós-Graduação Stricto Sensu da Universidade Federal do Piauí, Brasil.

URL: https://orcid.org/0000-0003-4486-7565

E-mail: ludgleydson@yahoo.com.br 